\title{
Pedestrian Exposure to Air Pollution in Cities: Modeling the Effect of Roadside Trees
}

\author{
Jorge Humberto Amorim, Joana Valente, Pedro Cascão, Vera Rodrigues, \\ Cláudia Pimentel, Ana I. Miranda, and Carlos Borrego
}

CESAM \& Department of Environment and Planning, University of Aveiro, 3810-193 Aveiro, Portugal

Correspondence should be addressed to Jorge Humberto Amorim; amorim@ua.pt

Received 3 May 2013; Revised 28 August 2013; Accepted 2 September 2013

Academic Editor: Panagiotis Nastos

Copyright (c) 2013 Jorge Humberto Amorim et al. This is an open access article distributed under the Creative Commons Attribution License, which permits unrestricted use, distribution, and reproduction in any medium, provided the original work is properly cited.

\begin{abstract}
The exposure of students to traffic-emitted carbon monoxide (CO) in their daily walk to school is evaluated, with a particular emphasis on the effect of trees and route choice. The study is focused on the city centre of Aveiro, in central Portugal. Time evolution of the georeferenced location of an individual is tracked with a GPS for different alternative walking routes to a school. Spatial distribution of CO concentration is simulated with a computational fluid dynamics (CFD) model. An exposure model is developed that associates the georeferenced location of the student with the computed air quality levels (at an average breathing height) for that specific grid cell. For each individual, the model calculates the instantaneous exposure at each time frame and the mean value for a given period. Results show a general benefit induced by the trees over the mean exposure of the student in each route. However, in the case of instantaneous exposure values, this is not consistent along the entire period. Also, the variability of the estimated exposure values indicates the potential error that can be committed when using a single value of air quality as a surrogate of air pollution exposure.
\end{abstract}

\section{Introduction}

According to the United Nations Environment Programme (UNEP) information in 2009 [1], at least 1 billion people are exposed to outdoor air pollution that exceeds the air quality standards of the World Health Organization (WHO). Poor air quality in urban areas, mainly associated with the transportation sector, has been directly linked to almost 0.8 million premature deaths annually, especially in sensitive groups as children [1].

In urban areas, motor vehicles are a significant source of air pollution, and, despite the achieved technological progress in reducing motor emissions, there is a continuous growth in the world's motor-vehicle fleet and consequently an increase in the total traffic-related emissions. Motor vehicles emit large quantities of air pollutants (such as carbon monoxide $(\mathrm{CO})$, hydrocarbons $(\mathrm{HC})$, nitrogen oxides $\left(\mathrm{NO}_{x}\right)$, particulate matter (PM), benzene, formaldehyde, and acetaldehyde) that have a negative impact on human health and contribute to the formation of by-products such as ozone $\left(\mathrm{O}_{3}\right)$ and secondary aerosols. Noncombustion emissions from these vehicles should also be taken into account since road dust, tire, and break wear contain chemical compounds that may pose risk to human health. Due to the high amount of air pollutants released by traffic and the difficulty in quantifying them, taking all into account, it is common to use trafficpollutant surrogates such as $\mathrm{CO}, \mathrm{NO}_{2}$, or benzene in exposure studies [2].

Since the 1990s numerous studies have demonstrated the association between air pollutants concentration and the occurrence of health related problems [3-6]. In particular, some authors [7-10] have found associations between exposure to traffic and adverse health effects, such as hypertension, myocardial infarction, stroke, atherosclerosis, heart disease, and mortality. The majority of the studies on health effects from traffic exposure mostly rely on associations between hospital records and data from air quality monitoring stations, considered as representative of exposure in a large geographical area. Nevertheless, the health effects of air pollution are the result of a sequence of events, which include 


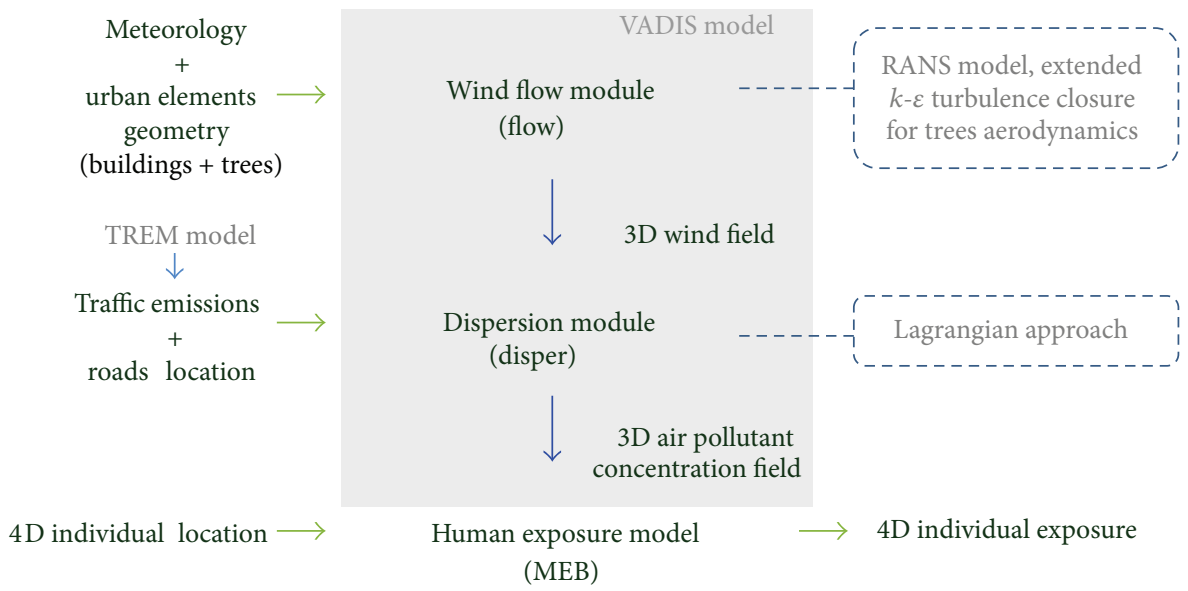

FIGURE 1: Schematic representation of modeling system architecture.

the release of pollutants, their transport and dispersion in the atmosphere, and their contact and uptake by humans. These events should be taken into account when performing a complete and correct assessment of human exposure. For that, one of the possible approaches is the use of numerical air quality models, which allow estimating spatial and temporal distribution of air pollutants [11], together with a microenvironment approach [12], for exposure estimation.

Although generally associated with environmental benefits, the presence of trees can also cause unwanted and unexpected outcomes on local air quality. It has been shown by field campaigns [13], wind-tunnel experiments [14], and numerical modeling $[15,16]$ that the complexity of the wind flow inside a given street-canyon is significantly increased by the presence of urban vegetation. The mechanisms behind the action of trees are based on the modification of the number and arrangement of vortical structures that characterize the turbulent recirculating flow between buildings, disrupting the vertical exchange rate of pollutants with the upper level atmosphere. Nevertheless, to the best of the authors' knowledge, the effect on the exposure of pedestrians resulting from perturbed air pollution dispersion induced by urban trees has not been addressed in the scientific literature.

This paper aims to evaluate the exposure of students to traffic-emitted CO in their daily walk to school and how it relates with the effect of trees and route choice.

\section{Model Development and Application}

2.1. Modeling System Description. With the purpose of evaluating the air pollution exposure of students in their morning walk to school, a local scale modeling system was used. This system (see Figure 1) includes two main models, one for simulating air quality and the other for estimating the individual exposure with time.

2.1.1. Air Quality Modeling. Local scale air quality modeling was carried out using the computational fluid dynamics (CFD) model VADIS [17]. In this model, the 3D wind flow is simulated by an RANS prognostic model with a standard $k-\varepsilon$ turbulence closure. For the dispersion, VADIS uses a Lagrangian approach. This model incorporates also the urban vegetation canopy module, URVE [18], which is intended for the simulation of the effect of vegetation over the wind flow and air pollutant dispersion. The main concept behind URVE involves the extension of the standard mean flow and turbulence equations, through the inclusion of additional source terms when coupled to a CFD model, allowing it to mathematically represent the effect of leaves and branches on the wind field. Consequently, the dispersion of the emitted air pollutants is conditioned by the disturbed wind flow, with effects that depend, most of all, on the characteristics of the vegetation itself and of the prevailing airflow. The loss of wind speed due to pressure and viscous drag forces exerted by the leaves an branches is accounted in the model as a source term that is added to the momentum conservation equation, which is dependent on the leaf area density (LAD) of each individual tree. Similarly, the turbulent interaction between the airflow and the plant canopy is addressed by including additional source terms in the transport equations of the turbulent kinetic energy and its dissipation. Model validation can be found in Section 3.1. For more details see Amorim et al. [18].

Road traffic emissions were estimated applying the transport emission model for line sources (TREM) [17], using detailed data on vehicles counting. Due to the short time and spatial scales of the analysis, $\mathrm{CO}$ can be considered as a nonreactive chemical species. Also, the $\mathrm{CO}$ removal by the canopy was neglected due to its insignificance (approximately $0.0015 \%$ of the CO concentration in ambient air according to Nowak et al. [19]).

2.1.2. Exposure Modeling. It is important to distinguish between the concepts of concentration and exposure. While the first is a physical characteristic of the environment at a given place and time, the latter quantifies the interaction between the polluted atmosphere and the person [20]. MEB [21], the exposure model used in this research, was developed with the objective of providing an estimate of the exposure of an individual to air pollution and being able to be used in both outdoor and indoor environments. 
TABLE 1: General description of the trees in the domain.

\begin{tabular}{lcc}
\hline Species & $\begin{array}{c}\mathrm{LAD} \\
\left(\mathrm{m}^{2} \cdot \mathrm{m}^{-3}\right)\end{array}$ & $\begin{array}{c}\text { Crown height range } \\
(\mathrm{m})\end{array}$ \\
\hline $\begin{array}{l}\text { Acer pseudoplatanus } \\
\text { and Quercus robur }\end{array}$ & 1.08 & $6-10$ \\
\hline
\end{tabular}

The MEB core is the calculation of personal exposure through the following general expression (which is a simplification from the microenvironment approach of Hertel et al. [12] since in this case only one microenvironment, outdoors, exists):

$$
\exp _{i}=C_{j} \times t_{i, j}
$$

where $\exp _{i}$ is the total exposure of the person $i$ over the specified period of time; $C_{j}$ is the pollutant concentration in a given location $j$; and $t_{i}$ is the time spent by the person $i$ in that specific location. As a result, the exposure value is expressed in concentration $\times$ time (e.g., $\left.\mu \mathrm{g} \cdot \mathrm{m}^{-3} \cdot \mathrm{min}\right)$ and thus can be interpreted as the mean pollutant concentration value to which the individual has been exposed during a given period of time.

The input data for this model is the following:

(i) the temporal variation of the individual location: this information was provided by a GPS equipment with a predefined temporal resolution (as it will be analysed in the following section);

(ii) the spatial distribution of concentrations at an average inhalation height for a given period of time.

By matching, in each time-step, the georeferenced position of the individual with the corresponding concentration, the model tracks the time evolution of the exposure. The output data produced by MEB are both instant and mean exposure values.

2.2. Model Application. This research was carried out in Aveiro, a medium sized town located in central Portugal, and is focused in the High School of "José Estêvão," including one of its most important traffic lanes, the " 25 de Abril" avenue, in front of the school.

The study domain has an area of approximately $0.4 \times$ $0.2 \mathrm{~km}^{2}$. The $3 \mathrm{D}$ configuration of the buildings and trees was virtually created in VADIS and the resulting computational domain is shown in Figure 2. The dimensions of the computational domain and the boundary conditions were defined following the recommendations from COST Action 732 [22] for the simulation of urban flows with multiple buildings. For more details on the air quality simulations see Amorim et al. [18].

Table 1 summarizes the information collected on trees. The LAD value was obtained from Lalic and Mihailovic [23].

A field campaign was carried out on May 5, 2004, which included meteorological measurements at the school front yard and road traffic counting in the main avenue ("25 de Abril") and in four other roads. CO concentrations were obtained from an "urban traffic" air quality monitoring
TABLE 2: Walking routes parameters (obtained from GPS tracking): maximum distance travelled; average walking speed; and the range of heights above mean sea level.

\begin{tabular}{lccc}
\hline Route & Distance $(\mathrm{m})$ & Mean speed $\left(\mathrm{km} \cdot \mathrm{h}^{-1}\right)$ & Elevation range $(\mathrm{m})$ \\
\hline A & 300 & 4.4 & $10-12$ \\
B & 315 & 4.9 & $12-15$ \\
C & 217 & 5.8 & $12-14$ \\
D & 333 & 5.0 & $9-12$ \\
\hline
\end{tabular}

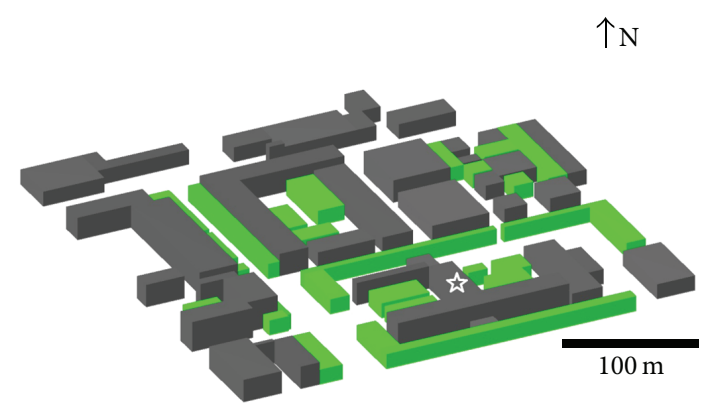

FIGURE 2: Computational domain generated by VADIS for the set of buildings (in grey) and trees (in green). The star indicates the location of the school.

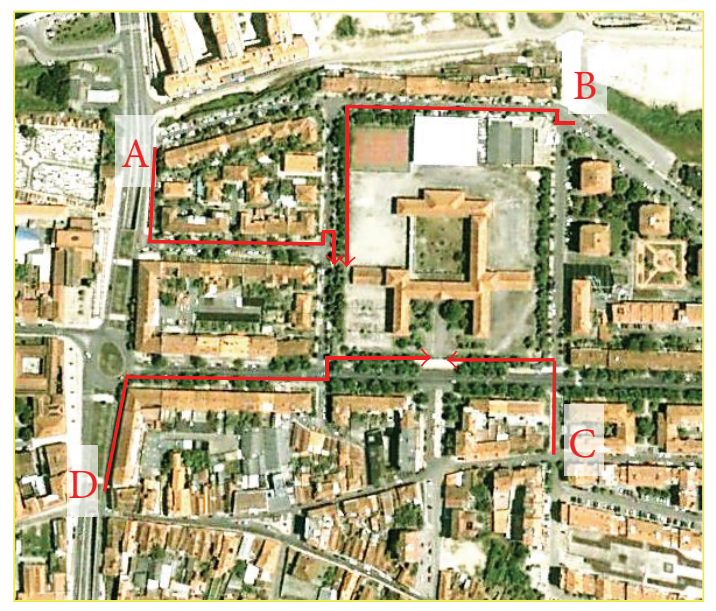

FIGURE 3: Tracked walking routes to school for exposure calculation.

station (AQS) of the national Portuguese network [24] that is located also in the school yard.

Four different walking routes to the school were defined (see Figure 3 ) and then tracked with a GPS equipment with a 10 -second time resolution. This procedure allowed to account for realistic walking speeds for each pathway and for the effect of potential delays caused by, for example, traffic lights in road traversing.

Table 2 characterizes the different routes according to the total distance covered by each individual, average walking speed, and elevation range.

With a mean speed of $5 \mathrm{~m} \cdot \mathrm{s}^{-1}$ (std. dev.: $0.6 \mathrm{~m} \cdot \mathrm{s}^{-1}$ ) and a mean distance of $291 \mathrm{~m}$ (std. dev.: $51 \mathrm{~m}$ ), no significant differences exist between the four routes, except for the traffic volume of each road. 


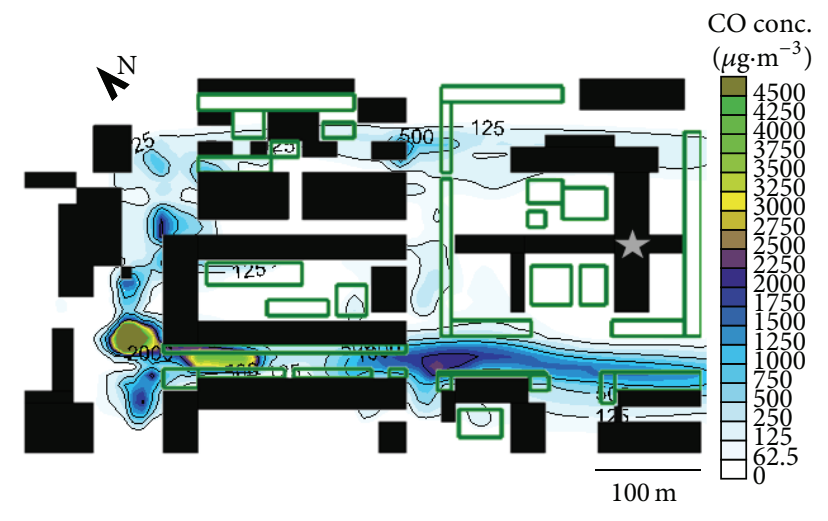

(a)

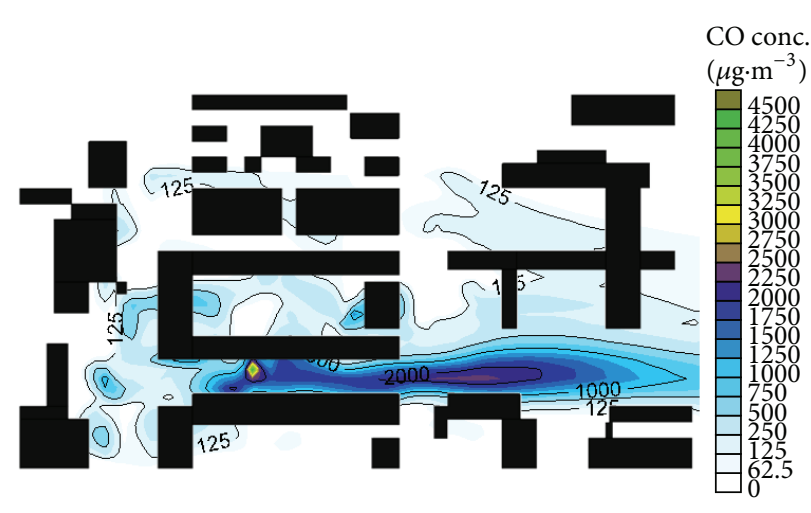

(b)

FIGURE 4: Comparison of $3 \mathrm{~m}$ high horizontal CO concentration fields with (a) and without (b) the effect of trees (in green) for the period between 8 and 9 a.m. The star indicates the location of the school.

In order to evaluate the effects induced by the vegetation canopy, the modeling system shown in Figure 1 was applied with the URVE module activated and deactivated. Simulations correspond to the hourly period between 8 and 9 a.m., which comprises the start of classes in the morning.

\section{Results and Discussion}

Results are analysed in the following sections in terms of local air quality and individual exposure attained on each route.

3.1. Air Quality. In order to validate the modeling results, we have compared the simulated hourly averaged values of $\mathrm{CO}$ concentration and wind velocity against the observed data for the period between 5 p.m. on May 4 and 12 p.m. of the next day. For this entire period, the normalized mean squared error (NMSE) obtained was 0.04 and the correlation coefficient was 0.9. All the statistical metrics calculated fulfill the model acceptance criteria defined by Chang and Hanna [25] for air quality model assessment. The modeling uncertainty was $19 \%$, fulfilling the data air quality objective established by the Directive 2008/50/CE. We have also concluded that the model performance increased when the effect of trees was taken into account. Additional details on the validation of the air quality simulations can be found in Amorim et al. [18].

In an inhomogeneous urban canopy the magnitude of the effect of trees on air quality is mostly determined by the characteristics of buildings and trees and by the angle between the prevailing wind and the street-canyons. This heterogeneous role of trees leads to specific areas benefiting from their action over the wind flow and dispersion while others have their ventilation capacity diminished (thus, promoting the formation of air pollution hot-spots). These effects are evident in the CO concentration patterns shown in Figure 4.

Figure 4(a) shows that the CO emitted by traffic in the " 25 de Abril" avenue is partially "contained" by the rows of trees in the sidewalks, causing an air quality improvement at the school front yard. On the contrary, without the windbreak action induced by trees the pollutant is more easily dispersed into the school, as shown in Figure 4(b). It should be noted that as a consequence of the "barrier effect" shown in Figure $4(\mathrm{a})$, a clear hot-spot is formed on the left end of the avenue, highlighting the strong spatial heterogeneity of the impacts of trees on urban air quality.

3.2. Human Exposure. In Figure 5, the evolution of the CO exposure is presented for the considered walking routes.

The differences in the magnitude of the exposure shown in Figure 5 are notorious, revealing that the individuals approaching the school from north (A and B) are exposed to much lower levels of $\mathrm{CO}$ than the others, which is a direct consequence from the lower traffic levels in the northern area.

Opposite effects of trees are found in routes $\mathrm{C}$ and $\mathrm{D}$. The inflection points (corresponding to instant $55 \mathrm{~s}$ after departure in C and $115 \mathrm{~s}$ in D) correspond to the arrival of child C at the main avenue and to the moment in which child $\mathrm{D}$, after entering the avenue, leaves the hot-spot at its left end (shown in Figure 4(a)). This allows to conclude that the presence of vegetation has no linear effect on the exposure values. This result is, in fact, consistent with the conclusion drawn from the comparative analysis of the air quality fields (in Figure 4), where no absolute tendency was observed.

As it can be seen from Figure 5, the values of the individual exposure to CO vary significantly with route and time, ranging from values close to zero to nearly $260 \mu \mathrm{g} \cdot \mathrm{m}^{-3} \cdot \mathrm{min}$. From this fact it can be concluded that even in a small domain, a significant error can occur if a mean air quality value is used as a proxy for the exposure of the individuals that use that space.

A comparison between the different profiles is shown in the box plot of Figure 6. In all routes the trees promote a decrease of the mean exposure value. Except in D, peak values are also decreased by the vegetation.

Additionally, Figure 7 shows the variation rate of the mean exposure that is induced by trees. The results shown in Figure 7 indicate a consistent decrease in exposure caused by trees. As can be seen by the comparison with Figure 6, maximum differences are found for lower exposure levels.

\section{Conclusions}

As shown by the CFD simulations, the individual exposure of pedestrians (which is closely linked with the local air quality) 


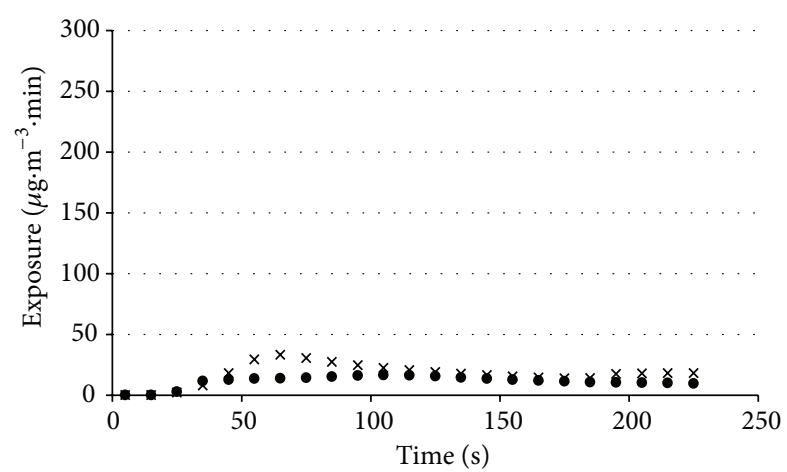

(a)

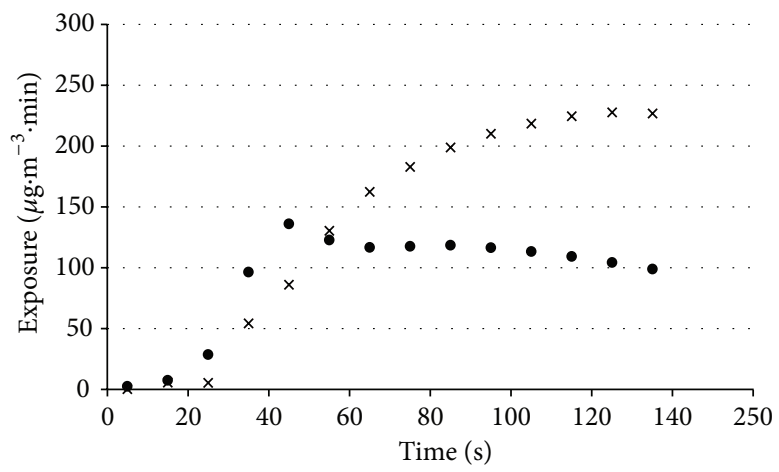

- Vegetation

$\times$ No vegetation

(c)

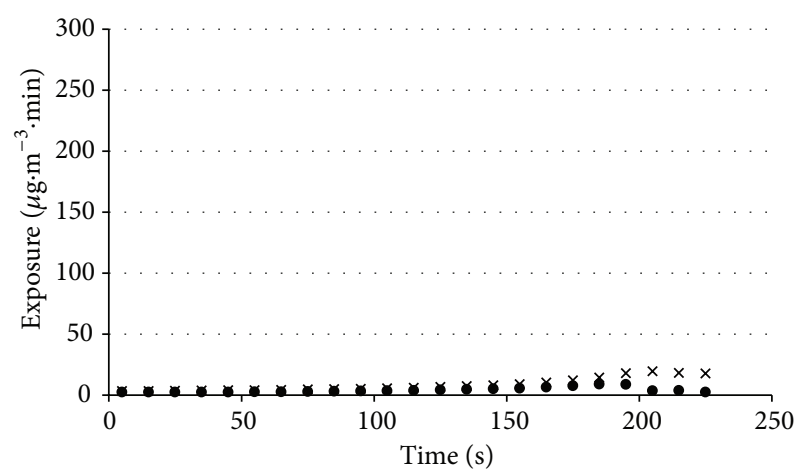

(b)

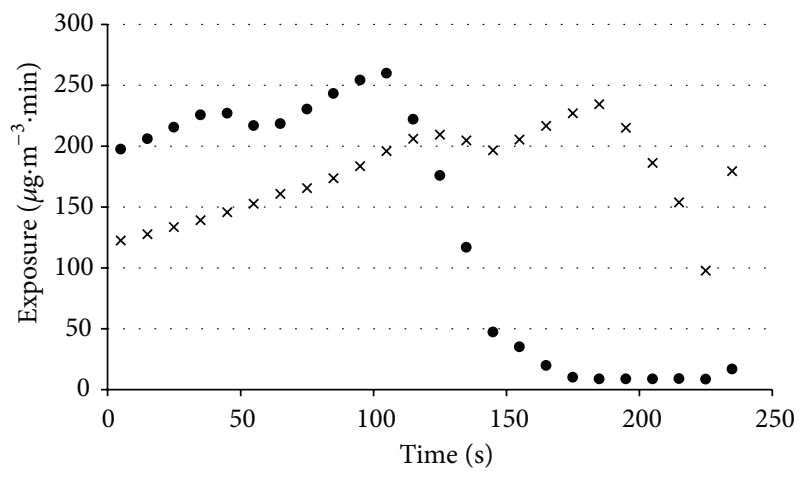

- Vegetation

$\times$ No vegetation

Figure 5: Time evolution of the individual exposure $\left(\mu \mathrm{g} \cdot \mathrm{m}^{-3} \cdot \mathrm{min}\right)$ to $\mathrm{CO}$ for each of the four considered pathways, with and without the presence of trees.

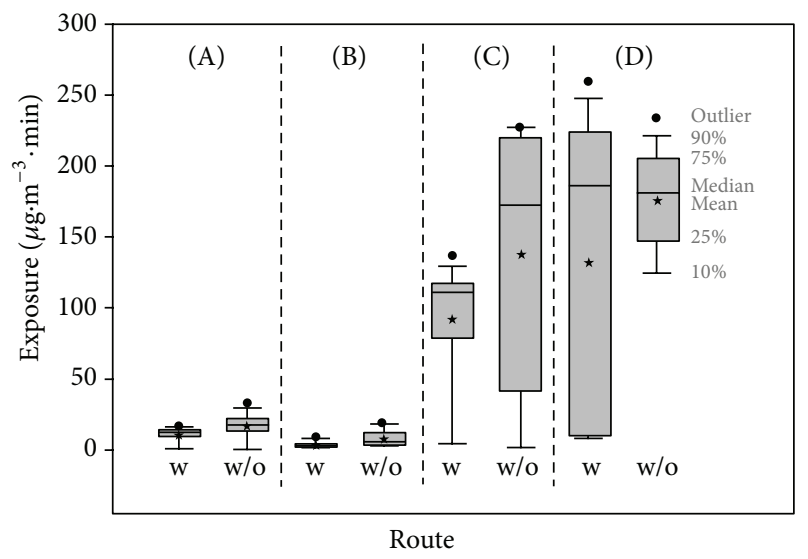

Figure 6: Box plot of the simulated exposure values for each route, comparing the results obtained with (w) and without (w/o) the influence of trees.

is strongly dependent on the synergies between the meteorological conditions, the three-dimensional configuration of the street-canyons, and the presence of vegetation. The effect of the urban canopy (as a mosaic of buildings and trees) on the dispersion of air pollutants, and resulting exposure,

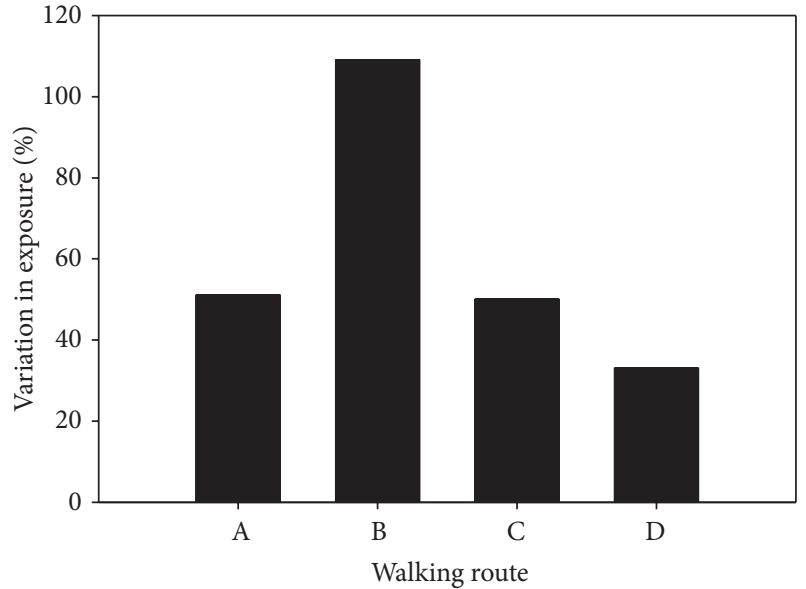

FIGURE 7: Comparison of the effect of trees on the personal exposure in each walking route. The variation in exposure was calculated as follows: $\left[\left(\mathrm{EXP}_{\text {notrees }}-\mathrm{EXP}_{\text {trees }}\right) / \mathrm{EXP}_{\text {trees }}\right] \times 100$, where $\mathrm{EXP}_{\text {notrees }}$ is the average exposure calculated without the effect of trees and $\mathrm{EXP}_{\text {trees }}$ is the average exposure with the presence of trees.

was shown to be complex and highly spatially dependent. The variability of the exposure results obtained in this study indicates the potential error that can be committed when 
a single value of air quality is used as a surrogate of air pollution exposure. This conclusion is valid for a small domain, such as the one studied in this work, and it can be easily concluded that the error may be significantly higher when larger domains are considered.

The fact that the presence of vegetation may have opposite effects on air quality, and consequently on pedestrian exposure, clearly indicates that, aiming at the improvement of public health, exposure studies are worth to be developed when a planning intervention is envisioned. The simulation of different planning alternatives, where the position and type of vegetation are explored in terms of its effect on air quality and exposure, should be supported by tools, as CFD models, that allow an enhanced understanding of the symbiosis between the city morphology and the citizen dynamics. This is a needed step towards healthier and sustainable future cities.

\section{Acknowledgments}

The authors would like to acknowledge the financial support of the 3rd European Framework Program and the Portuguese Ministry of Science, Technology and Higher Education, through the Foundation for Science and Technology (FCT), for the Postdoc grants of Jorge Humberto Amorim (SFRH/ BPD/48121/2008) and Joana Valente (SFRH/BPD/78933/ 2011) and for the funding of research project INSPIRAR (PTDC/AAC-AMB/103895/2008), supported in the scope of the Competitiveness Factors Thematic Operational Programme (COMPETE) of the Community Support Framework III and by the European Community Fund FEDER. This work was also partly supported by COST Action FP1204 "Green Infrastructure approach: linking environmental with social aspects in studying and managing urban forests."

\section{References}

[1] UNEP, Concept Paper for Workshop on Partnership for Clean Fuels and Vehicles for East Asia, United Nations Environment Programme, and Regional Resource Center for Asia and Pacific, 2009.

[2] HEI Panel on the Health Effects of Traffic-Related Air Pollution, "Traffic-related air pollution: a critical review of the literature on emissions, exposure, and health effects," HEI Special Report 17, Health Effects Institute, Boston, Mass, USA, 2010.

[3] A. Seaton, W. MacNee, K. Donaldson, and D. Godden, "Particulate air pollution and acute health effects," The Lancet, vol. 345, no. 8943, pp. 176-178, 1995.

[4] J. M. Samet, F. Dominici, F. C. Curriero, I. Coursac, and S. L. Zeger, "Fine particulate air pollution and mortality in 20 U.S. cities, 1987-1994," The New England Journal of Medicine, vol. 343, no. 24, pp. 1742-1749, 2000.

[5] WHO, Development of WHO Guidelines for Indoor Air Quality, Report on a Working Group Meeting, World Health Organization Regional Office for Europe, 2007.

[6] C. A. Pope III and D. W. Dockery, "Health effects of fine particulate air pollution: lines that connect," Journal of the Air and Waste Management Association, vol. 56, no. 6, pp. 709-742, 2006.
[7] M. M. Finkelstein, M. Jerrett, and M. R. Sears, "Traffic air pollution and mortality rate advancement periods," The American Journal of Epidemiology, vol. 160, no. 2, pp. 173-177, 2004.

[8] G. Hoek, B. Brunekreef, S. Goldbohm, P. Fischer, and P. A. van den Brandt, "Association between mortality and indicators of traffic-related air pollution in the Netherlands: a cohort study," The Lancet, vol. 360, no. 9341, pp. 1203-1209, 2002.

[9] B. Hoffmann, S. Moebus, S. Möhlenkamp et al., "Residential exposure to traffic is associated with coronary atherosclerosis," Circulation, vol. 116, no. 5, pp. 489-496, 2007.

[10] C. Tonne, S. Melly, M. Mittleman, B. Coull, R. Goldberg, and J. Schwartz, "A case-control analysis of exposure to traffic and acute myocardial infarction," Environmental Health Perspectives, vol. 115, no. 1, pp. 53-57, 2007.

[11] C. Borrego, O. Tchepel, A. M. Costa, H. Martins, J. Ferreira, and A. I. Miranda, "Traffic-related particulate air pollution exposure in urban areas," Atmospheric Environment, vol. 40, no. 37, pp. 7205-7214, 2006.

[12] O. Hertel, F. A. A. M. de Leeuw, O. Raaschou-Nielsen et al., "Human exposure to outdoor air pollution (IUPAC technical report)," Pure and Applied Chemistry, vol. 73, no. 6, pp. 933-958, 2001.

[13] A. Kikuchi, N. Hataya, A. Mochida et al., "Field study of the influences of roadside trees and moving automobiles on turbulent diffusion of air pollutants and thermal environment in urban street canyons," in Proceedings of the 6th International Conference on Indoor Air Quality, Ventilation and Energy Conservation in Buildings (IAQVEC '07), pp. 137-144, Sendai, Japan, October 2007.

[14] C. Gromke and B. Ruck, "On the impact of trees on dispersion processes of traffic emissions in street canyons," BoundaryLayer Meteorology, vol. 131, no. 1, pp. 19-34, 2009.

[15] A. Mochida, Y. Tabata, T. Iwata, and H. Yoshino, "Examining tree canopy models for CFD prediction of wind environment at pedestrian level," Journal of Wind Engineering and Industrial Aerodynamics, vol. 96, no. 10-11, pp. 1667-1677, 2008.

[16] R. Buccolieri, C. Gromke, S. Di Sabatino, and B. Ruck, "Aerodynamic effects of trees on pollutant concentration in street canyons," Science of the Total Environment, vol. 407, no. 19, pp. 5247-5256, 2009.

[17] C. Borrego, O. Tchepel, A. M. Costa, J. H. Amorim, and A. I. Miranda, "Emission and dispersion modelling of Lisbon air quality at local scale," Atmospheric Environment, vol. 37, no. 37, pp. 5197-5205, 2003.

[18] J. H. Amorim, V. Rodrigues, R. Tavares, J. Valente, and C. Borrego, "CFD modelling of the aerodynamic effect of trees on urban air pollution dispersion," Science of the Total Environment, vol. 461-462, pp. 541-551, 2013.

[19] D. J. Nowak, D. E. Crane, and J. C. Stevens, "Air pollution removal by urban trees and shrubs in the United States," Urban Forestry and Urban Greening, vol. 4, no. 3-4, pp. 115-123, 2006.

[20] W. R. Ott, "Concepts of human exposure to air pollution," Environment International, vol. 7, no. 3, pp. 179-196, 1982.

[21] A. I. Miranda, J. H. Amorim, V. Martins et al., "Modelling the exposure of firefighters to smoke based on measured data," in Proceedings of the $3 \mathrm{rd}$ International Conference on Modelling, Monitoring and Management of Forest Fires, 2011.

[22] J. Franke, A. Hellsten, H. Schlünzen, and B. Carissimo, Best Practice Guideline for the CFD Simulation of Flows in the Urban Environment, COST Action 732, Quality Assurance and Improvement of Microscale Meteorological Models, COST Office, 2007. 
[23] B. Lalic and D. T. Mihailovic, "An empirical relation describing leaf-area density inside the forest for environmental modelling," Journal of Applied Meteorology, vol. 43, no. 4, pp. 641-645, 2004.

[24] APA, Air Quality Data for Portuguese Monitoring Stations, APA, Lisbon, Portugal, 2011, http://www.qualar.org/.

[25] J. C. Chang and S. R. Hanna, Technical Descriptions and User's Guide for the BOOT Statistical Model Evaluation Software Package, version 2.0, 2005. 

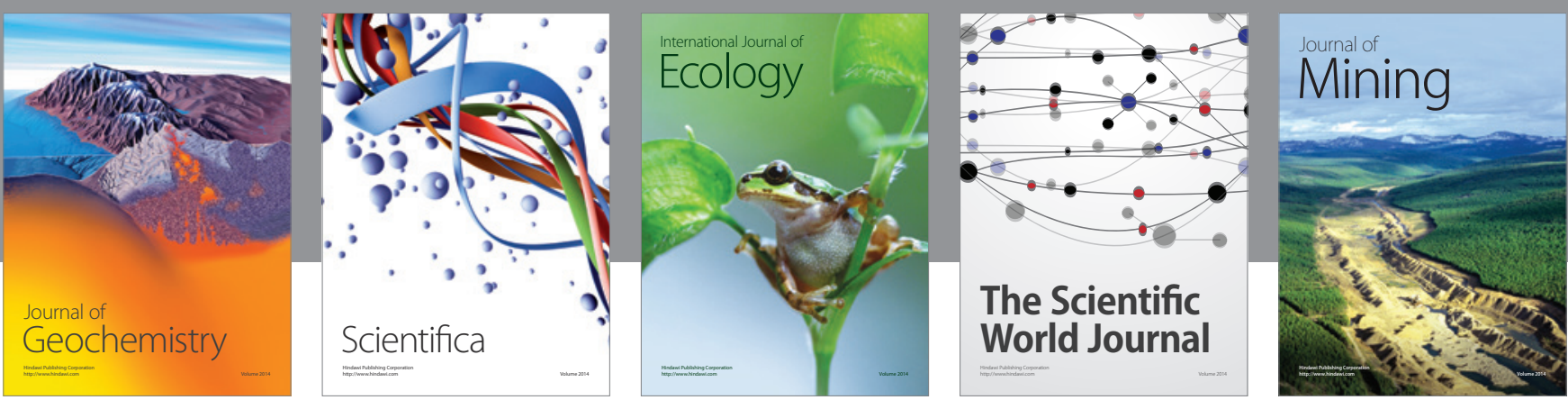

The Scientific World Journal
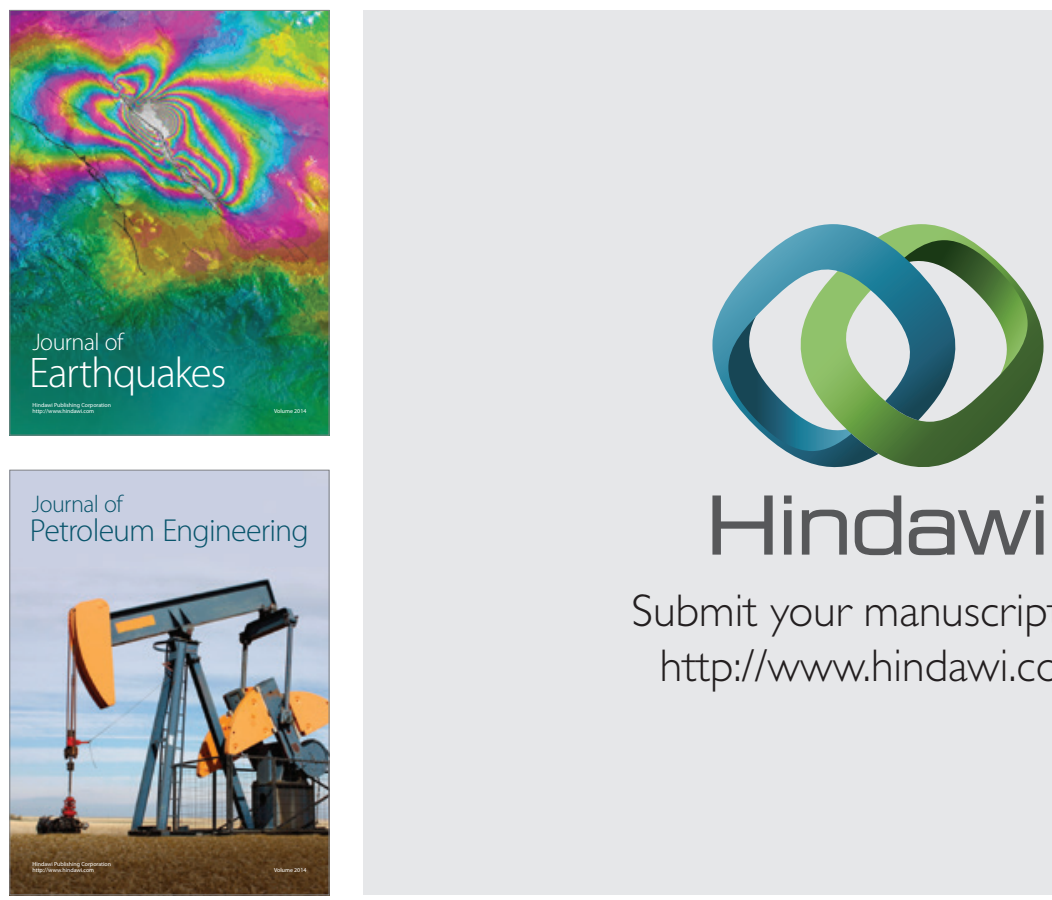

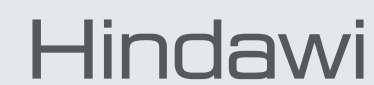

Submit your manuscripts at

http://www.hindawi.com
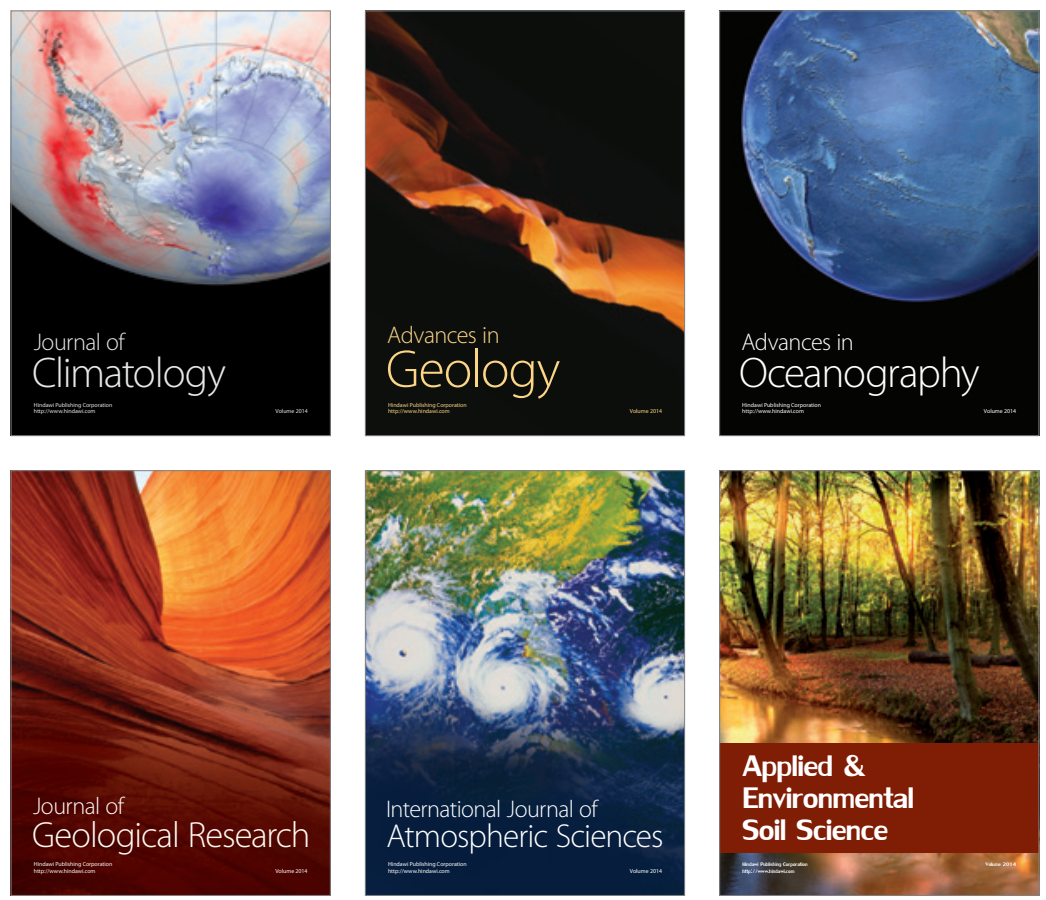
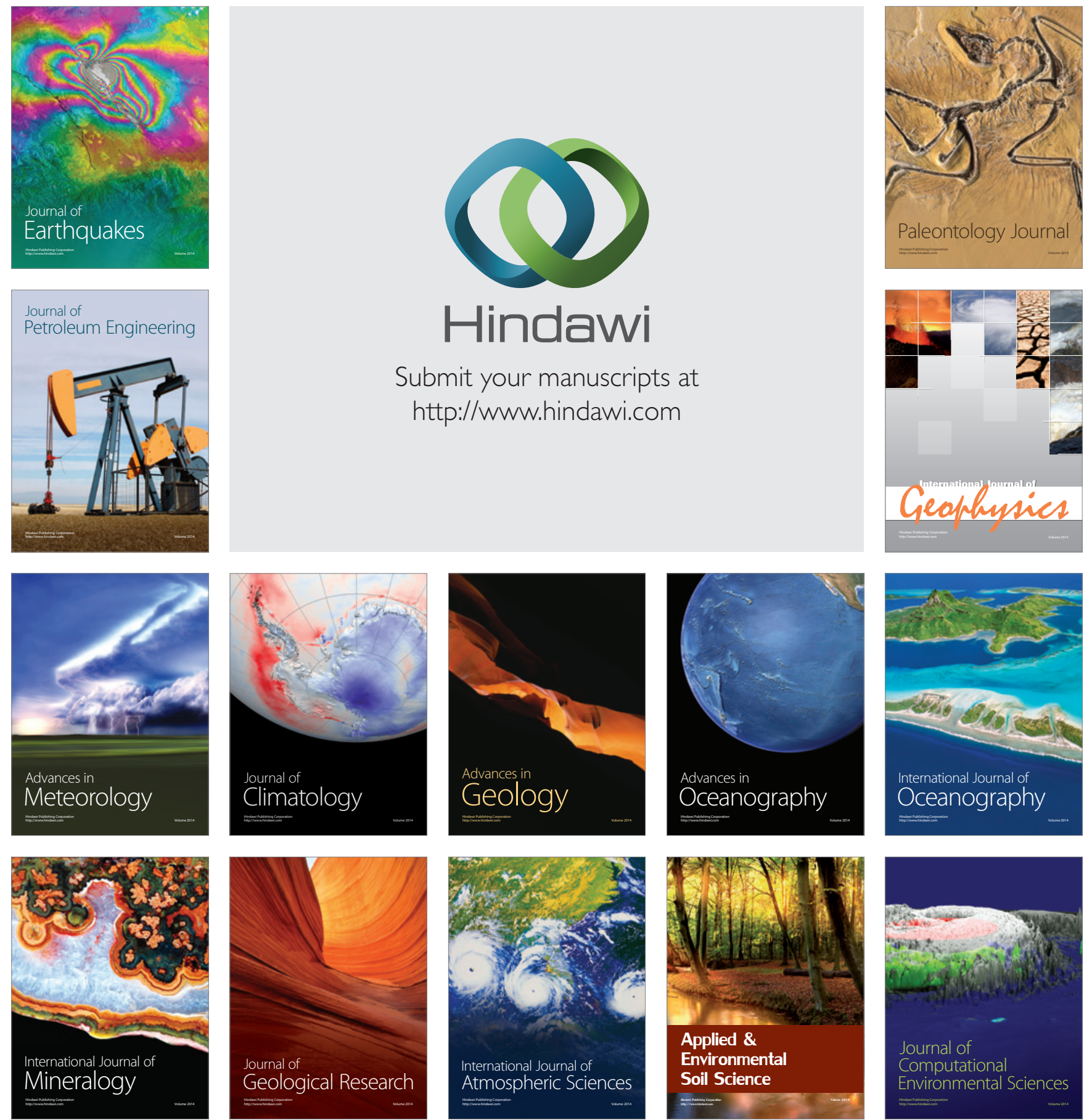